\title{
XVIII. Preliminary investigations on Silberstein's quantum theory of photographic exposure
}

\section{A.P.H. Trivelli \& L. Righter}

To cite this article: A.P.H. Trivelli \& L. Righter (1922) XVIII. Preliminary investigations on Silberstein's quantum theory of photographic exposure , Philosophical Magazine Series 6, 44:259, 252-256, DOI: 10.1080/14786440708633991

To link to this article: http://dx.doi.org/10.1080/14786440708633991

曲 Published online: 08 Apr 2009.

Submit your article to this journal $[\pi$

Џll Article views: 1

Q View related articles $\square$

Citing articles: 6 View citing articles 5 
distance of the centre of buoyancy $B$ (the centroid of the displaced liquid) from the metacentre $M$ is given by $\mathrm{BM}=\mathrm{AK}^{2} / V$, where $\mathrm{V}$ is the volume of the displaced liquid and $A K^{2}$ is the moment of inertia of the water-line area about the intersection of the wedges of emersion and immersion. The equilibrium of the floating body is stable if

Fig. 8.

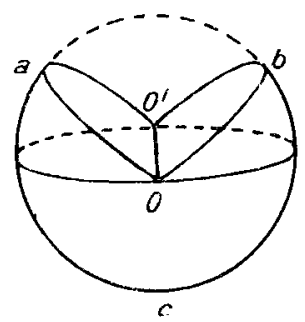

Fig. 9.

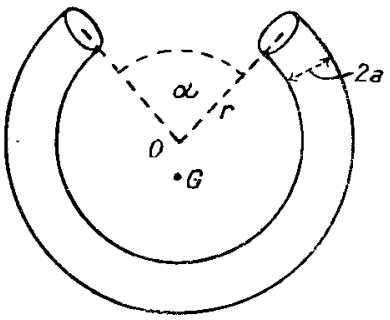

$M$ is above $G$, the centroid of the floating body, that is if $B M>B G$; it is unstable if $B M<B G$; and it is neutral if $\mathrm{BM}=\mathrm{BG}$, that is when $\mathrm{M}$ coincides with $\mathrm{G}$. In figure 5 we may suppose the complete cylinder floating in water so that abcd is the water-line area. The cylinder is obviously in neutral equilibrium so far as turning about the axis $O O^{\prime}$ is concerned. Thus M lies in the line $\mathrm{OO}^{\prime}$, and we have

$$
\mathrm{OG}=\frac{\mathrm{AK}^{2}}{\mathrm{~V}} \text {. }
$$

University of Glasgow, May $1,1922$.

XVIII. Preliminary Investigations on Silberstein's Quantum Theory of Photographic Exposure. By A. P. H. Triveldi and L. RIGH'TER *.

\section{Introductory.}

7 THIS paper is the first of a number of investigations now being conducted in this laboratory to test experimentally the light-quantum theory of photographic exposure recently proposed by Dr. Silberstein before the Toronto meeting of the American Physical Society.

* Communication No. 141 from the Research Laboratory of the Eastman Kodak Company. 
Originally, these experiments were started independently of that theory, our intention being primarily to study the effect of the clumping, or clustering together in groups, of silver halide grains in a photographic emulsion *. According to Slade and Higson $t$, "It seems reasonable to assume that each grain acts quite independently and that one grain which has become developable is unable to make a grain, situated in close proximity to it, developable unless the latter grain is developable in itself." From the table (p. 256) it is readily seen that this statement is not true, but the grains when elumped together act as one grain for development to the limit.

Since each clump acts as one grain a very much broader range of grain sizes, or their equivalent, is obtained extending from the smallest single grains up to the largest clumps (containing 30 or more grains) in a given emulsion.

It was thought that these results afforded a rigorous test for Silberstein's theory, and it seemed therefore worth while to compare them with the implications of that theory.

Silberstein's fundamental formula is essentially, $i$. e. apart from chromatic complications, and disregarding the lateral dimensions of the light quanta,

$$
\frac{k}{\mathrm{~N}}=1-e^{-n a},
$$

where $\mathrm{N}$ is the original number, per unit of the plate, of the class of grains of size (area) $a, n$ the number of incident light-quanta, again per unit area of plate. and $k$ the number of grains affected $¥$. If the finite cross section $\sigma$ of the light-quantum is taken into account, $a$ is to be replaced by

$$
a^{\prime}=\alpha\left[1-\sqrt{\frac{\sigma}{a}}\right]^{2}
$$

At first, the rapid increase of $k$ with the size $a$ as required by that formula seemed (qualitatively speaking) not only attained but even exceeded by the experimental results. This seemed to us to indicate that the sizes (areas) of the clumps of grains were under-estimated by us. In fact, for

* Extensire experiments are being conducted in this laboratory to study the clumping of grains in different concentrations of the same emulsion. These investigations will be published later.

+ Slade and Higson, "Photochemical Investigations of the Photographic Plate." Proc. Roy. Soc. xeviii. p. 154 (1920).

† Silberstein, L., "Quantum Theory of Photographic Exposure," infìa, p. 257 . 


\section{Messis. Trivelli and Righter on Silberstein's}

an estimate of the areas of all clumps one and the same average grain size (area) had been assumed throughout. Upon recalculating the results, however, and assigning the correct average grain size (area) to the single grains and to the different clumps, the very interesting fact was ohserved that the average grain size (area) increases from the single grains to the clumps of two three, etc. The corrected results conform, even better than expected, to the above formula, with a finite $\sigma$.

\section{Eixperimental.}

These experiments, although of an extremely tedious and trying nature, were performed with the utmost care and, to the best of our knowledge, all sources of error were either eliminated or reduced to a minimum. Only a brief description of the experimental procedure will be given at this time, as a more extensive paper containing further experimental results is to be published in the near future with a detailed account of our methods of photomicrography, and in which all errors will be discussed fully.

A simple silver bromide emul-ion was used for these experiments having a speed of 112 and gamma 0.8 for six minutes development in an ordinary pyro-soda developer at $17^{\circ} \mathrm{C}$. The average size of the grain is about $0.9 \mu$ diameter.

The method of preparation of strips for sensitometric exposure is, briefly, as follows :- One 5 in. $\times 7$ in. plate of the original emulsion is soaked in distilled water for one half-hour at $0^{\circ} \mathrm{C}$. to $8^{\circ} \mathrm{C}$. (All work for sensitometric exposure was done in a dark room by the aid of a dull red safelight, Wratten Series 2). The water is removed and a warm solution of gelatine, alcohol, and water is added and the whole solution heated in an oven for 20 minutes, while care is being taken not to heat over $40^{\circ} \mathrm{C}$., because above this temperature much fogging takes place. With several such applications of the aforesaid solution the emulsion is entirely removed from the plate and the resulting solution made up to such a volume that it will give one laver of grains upon coating and drying. Some of the slides are used at once to get the clump frequency data. Those for exposure are backed with an opaque substance to prevent reflexions, then exposed in a sensitometer, developed to gamma infinity with a pyro-soda developer at $17^{\circ} \mathrm{O}$., washed, and the developed silver removed with a dilute solution of chromic acid and 
sulphuric acid. The strips thus obtained contain the undeveloped grains, and by taking the difference the number of developed grains is calculated.

The data given below cover only the first or highest density step of a Hurter and Driffield sensitometric strip*. 20 fields on each of 3 strips are employed to determine the developed grains. To determine the number of grains and clumps in the original one grain layer plate before sensitometric exposure and development, 10 fields on each of 4 strips were used. By taking this large number of fields on several strips we obtained a much better average. The results in both the above cases are reduced to a number of grains or clumps per square centimetre of one grain layer plate. Then as the dilution is known, one may, with certain restrictions, refer back to the original plate.

All photomicrographs were made at a magnification of 2500 diameters and these negatives enlarged 4 times in printing. On the prints the grains and clumps are measured and counted, and then classified in class sizes (areas). The class sizes (areas) are 0 to $0.2 \mu^{2}, 0.2$ to $0.4 \mu^{2}, 0.4$ to $0.6 \mu^{2}$, etc. The light source is a point source from a Pointolite lamp which is screened with a Wratten $(\mathrm{H})$ blue filter to restrict the wave-length range and therefore increase the resolving power of the microscope. A cell containing copper sulphate solution absorbs heat rays and a cell containing a solution of quinine bisulphate excludes the ultraviolet light. The optical system is built up as follows : Cedar oil immersion condenser and objective, aplanatic condenser of numerical aperture $1 \cdot 4$, and Bausch and Lomb objective $1.9 \mathrm{~mm}$. numerical aperture 1.3 in combination with a No. 6 compensating ocular.

In the following is a table of our results. Column 1 contains the number of grains in each clump, column 2 the average area of grains in corresponding clumps, column 3 the number of grains times $10^{-3}$ per square centimetre of original one-grain layer plate, column 4 the number of grains times $10^{-3}$ per square centimetre of developed onegrain layer plate, and column $\breve{5}$ gives the proportionate number $\frac{k}{\mathrm{~N}}$ of clumps affected.

* The five remaining steps each corresponding to one-half the exposure of the preceding are now being counted and mapped out, and we hope to be able to publish the results obtained with them in the course of one or two months. 


\begin{tabular}{|c|c|c|c|c|}
\hline $\begin{array}{l}\text { Number of } \\
\text { Grains } \\
\text { in Clump. }\end{array}$ & $a$ in $\mu^{2}$ & $\begin{array}{l}\text { N. } 10^{-3} \text { per } \\
\text { sq. cm. } 1 \text { grain } \\
\text { layer plate } \\
\text { (originai). }\end{array}$ & $\begin{array}{l}k .10^{-3} \text { per } \\
\text { sq. om. } 1 \text { grain } \\
\text { layer plate } \\
\text { (developed). }\end{array}$ & $\begin{array}{l}k \\
\bar{N}\end{array}$ \\
\hline $1 .$. & $0 \cdot 75^{4}$ & 65770 & $1086 \cdot 0$ & $0 \cdot 165$ \\
\hline $2 \ldots \ldots \ldots$ & $1.92^{5}$ & $1322 \cdot 0$ & $594 \cdot 0$ & 0449 \\
\hline $3 \ldots \ldots \ldots$ & $3 \cdot 03$ & $664: 0$ & $508 \cdot 6$ & $0 \cdot 766$ \\
\hline $4 \ldots \ldots \ldots$ & $4 \cdot 88^{1}$ & $328 \cdot 0$ & $286 \cdot 3$ & $0-871$ \\
\hline $5 \quad \ldots \ldots \ldots$ & $6.18\}$ unreliable & 2499 & $240 \cdot 0$ & $0-960$ \\
\hline $6, \ldots \ldots \ldots$ & $7 \cdot 42\}$ unreliable & $157 \cdot 8$ & $155 \cdot 0$ & $0-982$ \\
\hline $7 \ldots \ldots \ldots$ & $8 \cdot 6$ & $105 \cdot 2$ & $105 \cdot 2$ & 1.000 \\
\hline $8 \ldots \ldots \ldots$ & $9 \cdot 8$ & $52 \cdot \overline{6}$ & $52 \cdot 6$ & 1.000 \\
\hline $9 \quad \ldots \ldots \ldots$ & $11 \cdot 0$ & 526 & $52 \cdot 6$ & $1 \cdot 000$ \\
\hline $10 \quad \ldots \ldots \ldots$ & 120 & 395 & $39 \cdot 3$ & 1000 \\
\hline $11 \ldots \ldots \ldots$ & $\cdots$ & $26 \cdot 3$ & $26 \cdot 3$ & $1 \cdot 000$ \\
\hline $12 \quad \ldots \ldots \ldots$ & $\ldots$ & $39 \cdot 5$ & $39 \cdot 5$ & 1.000 \\
\hline $13 \ldots \ldots \ldots$ & $\ldots$ & $19 \cdot 8$ & $19 \cdot 8$ & $1 \cdot 000$ \\
\hline $14 \ldots \ldots \ldots$ & $\ldots$ & $19 \cdot 8$ & $19 \cdot 8$ & $1 \cdot 000$ \\
\hline $15 \ldots \ldots \ldots$ & $\ldots$ & 6.5 & $6 \cdot 6$ & 1.000 \\
\hline $16 \ldots \ldots \ldots$ & $\ldots$ & $13 \cdot 2$ & $13 \cdot 2$ & 1.000 \\
\hline $17 \ldots \ldots \ldots$ & $\ldots$ & $13 \cdot 2$ & $13 \cdot 2$ & $1 \cdot 000$ \\
\hline $18 \ldots \ldots \ldots$ & $\ldots$ & $13 \cdot 2$ & $6 \cdot 5$ & $1 \cdot 000$ \\
\hline $19 \ldots \ldots \ldots$ & $\ldots$ & $6 \cdot 5$ & $3 \cdot 3$ & 1.000 \\
\hline $20 \ldots \ldots \ldots$ & $\ldots$ & $3 \cdot 3$ & 66 & 1.000 \\
\hline $21 \ldots \ldots \ldots$ & $\ldots$ & $6 \cdot 6$ & $13 \cdot 2$ & 1.000 \\
\hline $22 \ldots \ldots \ldots$ & $\ldots$ & $13 \cdot 2$ & $3 \cdot 3$ & 1.030 \\
\hline $23 \ldots \ldots \ldots$ & $\ldots$ & $3 \cdot 3$ & $1 \cdot 3$ & 1.000 \\
\hline $24 \ldots \ldots \ldots$ & $\ldots$ & 13 & $6 \cdot 6$ & 1.060 \\
\hline $25 \ldots \ldots \ldots$ & $\cdots$ & 66 & $1 \cdot 3$ & 1000 \\
\hline $26 \ldots \ldots \ldots$ & $\ldots$ & $1 \cdot 3$ & 0 & 1.000 \\
\hline $27 \ldots \ldots$ & $\ldots$ & 0 & $3 \cdot 3$ & $1 \cdot 000$ \\
\hline $28 \ldots \ldots \ldots$ & $\ldots$ & $3 \cdot 3$ & $\mathbf{0}$ & 1.000 \\
\hline $29 \ldots \ldots \ldots$ & $\ldots$ & 0 & 0 & $1 \cdot 000$ \\
\hline $30 \ldots \ldots \ldots$ & $\ldots$ & 0 & $1 \cdot 3$ & 1.000 \\
\hline $31 \ldots \ldots \ldots$ & . & $1 \cdot 3$ & $1 \cdot 3$ & 1.000 \\
\hline $32 \ldots \ldots \ldots$ & $24 \cdot 0$ & $1 \cdot 3$ & $1 \cdot 3$ & 1.000 \\
\hline $38 \ldots \ldots \ldots$ & $25 \cdot 0$ & $1 \cdot 3$ & $\cdots$ & $1 \cdot 000$ \\
\hline
\end{tabular}

The agreement of the numbers of the last column with those calculated by Silberstein's formula (with $\mathrm{N}=0.572$ and $\sigma=0.0973$ ), as given in his paper, is manifestly a very pronounced one. The differences between the observed and calculated values are even in the case of the 3 grain clumps entirely within the limits of experimental error, particularly concerning the area measurements.

In continuance of this work the theoretical formula will be subject to further tests, the results of which will be published shortly.

Rochester, N.Y.

January 24, 1922. 